\title{
El proyecto de vida: \\ Un desarrollo organizacional desde lo humano
}

Almeida García, Joel

Universidad de las Californias Internacional, México

joel.almeida@udc.edu.mx

Resumen - El objetivo de este ensayo es reflexionar sobre cómo un proyecto profesional favorece el desarrollo del individuo en los ámbitos organizacionales, en el cual se considere el enfoque humano. A través de abordar determinados teóricos sobre conceptos claves, como proyecto profesional, desarrollos organizacional y humano, se pretende responder a la interrogante si el proyecto de vida o profesional es un potenciador del desarrollo humano dentro de una organización. La conclusión nos da una aproximación a que la presencia del proyecto de vida desde la etapa universitaria favorece a la selección del centro de trabajo adecuado, que conlleve para la decisión para su permanencia, y así evitar o limitar sus capacidades en el entorno laboral.

Palabras clave - Proyecto de desarrollo; Objetivo educacional; Empleo del estudiante; Cultura del trabajo; Desarrollo humano;

Abstract - The objective of this essay is to reflect on how a professional project favors the development of the individual in organizational settings, in which the human approach is considered. By addressing certain theorists on key concepts, such as professional project, organizational and human development, it is intended to answer the question if the life or professional project is an enhancer of human development within an organization. The conclusion gives us an approximation that the presence of the life project from the university stage favors the selection of the appropriate work center,

Interconectando Saberes, 2021

ISSN: 2448-8704

(cc) $\mathrm{BY}-\mathrm{NC}-\mathrm{ND}$ which leads to the decision for their permanence, and thus avoid or limit their capacities in the work environment.

Keywords - Development projects; Educational objectives; Student employment; Culture of work; Human development;

\section{INTRODUCCIÓN}

La educación superior, en caso especial la universitaria, es la antesala para la vida laboral en la cual el egresado, o próximo a, le permita obtener un desarrollo que desde el enfoque económico y profesional aplique los conocimientos adquiridos durante sus estudios, sin embargo, el génesis de su desarrollo profesional puede mermar otro tipo de desarrollos.

Dada la idea anterior, el objetivo de este escrito es reflexionar sobre cómo un proyecto profesional favorece el desarrollo del individuo, en los ámbitos organizacionales, en el cual se considere el enfoque humano.

Fecha de Recepción: 05 de noviembre de 2020

Fecha de Aceptación: 18 de enero de 2021

Fecha de Publicación: 31 de enero de 2021 
A manera de inicio, el escrito tiene como corpus la estructura siguiente: en primera instancia la interrogante guía para el análisis, en segundo término, determinados teóricos son abordados a partir de sus análisis sobre conceptos claves, como proyecto profesional, desarrollos organizacional y humano, que, como conclusión, den respuesta a la interrogante.

Las transformaciones y cambios en la sociedad repercuten en diversas esferas sociales como la educativa y laboral, además, impactan en la forma de enfrentar los retos que conlleva pertenecer a una organización, por ejemplo, en las habilidades y destrezas para desarrollar las actividades que el puesto necesite.

De esta forma, la tesis del autor parte de que, si la inserción en el sector productivo es una evidencia de desarrollo humano para el egresado, por tanto ¿es el proyecto de vida o profesional un potenciador del desarrollo humano dentro de una organización?

\section{DESARROLLO}

El impacto de la publicidad coloca en pantalla de la sociedad las actividades culturales que, desde la perspectiva del autor, constituyen los rasgos que definen a la generación actual, por ejemplo en las formas de comunicación -dispositivos móviles-, entretenerse -contenido en línea o streaming-, hasta la apariencia -redes sociales como Instagram y Facebook-, entre otros y, por ende, pueden ser utilizados como cánones o ideales a seguir, pues favorecen a la demanda de roles de identidad y pertinencia.

Expresado en otros términos, los ideales ilusorios de las realidades digitales con relación al entorno social pueden propiciar una desvirtualización del individuo exitoso porque la imagen utópica del profesional contemporáneo empaña u omite aspectos como la experiencia laboral, es decir, la falta de familiaridad en ambientes laborales; así, pues, existe una repercusión en la selección de una fuente de trabajo que limita su desarrollo dentro de la organización, que queda evidenciada en la aceptación de sueldos bajos o, en su defecto, dádivas de horas trabajo, per se.

\section{Proyecto de vida}

Autores como Lomelí, López y Valenzuela (2016) sustentan que un proyecto de vida está compuesto por "saberes que abarcan todas las áreas de la vida, actitudes, construcción de conceptos fundamentales y competencias metodológicas generales" (p. 4).

En línea con la cita anterior, los proyectos de vida gestionados desde las instituciones superiores poseen una importancia porque proporcionan a los estudiantes herramientas para que construyan metas viables; el reto es la existencia de una relación transparente e intrínseca entre los planes y programas de estudio con las realidades laborales, en énfasis para las potenciales y cercanas al ámbito social del futuro egresado (Guerrero, Mejía y Zermeño, 2016). 
No obstante, el autor de este escrito considera que los elementos de un proyecto de vida individual consisten en la presencia de objetivos claros y posibles, además de contemplar las necesidades y expectativas personales que coadyuven a visualizar al egresado más allá de los conocimientos del ámbito escolar o de su alma máter, por tanto, es focalizar su atención hacia la selección del nuevo y adecuado ámbito social: el laboral.

\section{Desarrollo organizacional}

Por otra parte, Pérez (2016) define al desarrollo organizacional a partir de cómo se gestiona el capital humano en la organización, además de la integración de los miembros al entorno, su identificación con la institución, cómo se manifiesta su crecimiento personal y profesional, su motivación, productividad, entre otros.

Los ámbitos laborales facultan para que los estudiantes pongan en práctica los conocimientos adquiridos durante el estudio de su carrera profesional, esto, a cambio de una retribución económica; no obstante, el practicum en el ambiente de trabajo debe realizarse desde la etapa de formación universitaria (Beraza, 2017).

De este modo, el autor de este escrito considera que el desarrollo organizacional debe estar compuesto por las condiciones para que el trabajador -no limitado a egresado o estudiantetenga movilidad jerárquica en el puesto o centro de trabajo, y evitar apreciar al incremento económico como evidencia de superación, que dicho sea de paso la movilidad económica debe desarrollarse como una acción por de facto que cause una incentivación personal y sentido de pertenencia hacia el centro laboral.

Por consiguiente, el egresado universitario tendrá un alto compromiso si encuentra en su centro de trabajo oportunidades para desarrollar y potenciar sus competencias en vez de una continua praxis de conocimiento, además, el centro de trabajo obtiene a cambio un individuo absorbido por las dinámicas y logísticas de la organización quien es capaz, en un momento dado, aumentar la productividad porque el factor de pertenencia puede ser replicado por el resto del personal o, por lo menos, compañeros de área.

Por otra parte, el autor piensa que una actitud de apego organizacional desmedido puede frenar el desarrollo del individuo, pues con el afán de cumplir con las funciones solicitadas y demandadas, desatiende $u$ omite sus objetivos y capacidades porque en diversas situaciones sus actividades $-y$ actitudes- son mecanizadas.

\section{Desarrollo humano}

Por su parte, Nussbaum sostiene que el desarrollo humano debe considerarse desde la perspectiva de la dignidad humana, de un continente, país o región, la cual sea medible a través de las condiciones de vida sus habitantes (Posada, 2016). 
De la misma manera, Amartya Sen piensa con respecto al desarrollo humano como "la libertad de cada persona y los efectos de los mercados en la vida de las mismas" (Maldonado, 2019).

Es decir, Nussbaum y Sen presentan al desarrollo del individuo como un resultado de la influencia más allá de su ámbito social -in situ- sino la factibilidad de trasladar sus capacidades $y$ habilidades hacia otras esferas sociales; de ahí, pues, la importancia de considerar las condiciones del ámbito laboral proyectado antes de sujetarse o someterse a un compromiso, quizá duraderos, y sin retribuciones más allá que la recibida semanal, catorcenal o quincenal.

De acuerdo a lo comentado, los medios digitales tienen roles importantes en la sociedad como pantalla de ideales o gestores de identidad, aspecto que merma el desarrollo humano porque las decisiones individuales son perfiladas de acuerdo a estereotipos que en la mayoría son inalcanzables por los egresados, o bien proporcionan una sensación de falso logro porque en el momento que es confrontado con situaciones como el pago de impuestos, gastos personales, distribución económica mensual, entre otros, es cuando cae en cuenta la posible equívoca elecciones; sin duda, la principal fórmula para evitar las frustraciones personales dentro de una organización o centro de trabajo es el proyecto de vida.

\section{CONCLUSIÓN}

El objetivo de esta reflexión fue argumentar acerca de cómo un proyecto de vida favorece el desarrollo del individuo, en los ámbitos organizacionales, considerando el enfoque humano, en concreto una de las conclusiones es que la presencia del proyecto de vida desde la etapa universitaria favorece a la selección del centro de trabajo, así como la toma de decisión para su permanencia, y de esta forma evita limitar sus capacidades.

La dupla escuela y sector empresarial deben estar articulados para que los futuros profesionistas estudiante y empleado: transversalidad de rolespuedan desarrollar sus habilidades y capacidades, con el fin de asegurar una actividad productiva que beneficie al egresado como a su entorno.

La formación académica es el punto de partida para que los egresados perfilen el camino de su carrera hacia objetivos claros, coherentes y pertinentes a su realidad.

Por último, la consecuencia de que los ámbitos laborales consideren al egresado como una potencial inversión es un trabajador que encuentre in situ las condiciones para desarrollar su proyecto de vida, cuyos resultados o logros favorezcan a la organización, pues en un momento dado, las evidencias de logros y éxitos son sustanciosos para ciertos procesos de certificación y acreditación. Tal hecho, es sugerido continuar con una línea de estudio -de acción, de ser posible- en la cual los universitarios elaboren o diseñen proyectos de vida 
y los centros laborales, desde el enfoque humano, implementen estrategias para conocer el alcance de las capacidades de sus colaboradores y cómo ser partícipes de su desarrollo organizacional.

\section{REFERENCIAS}

Beraza, M. A. Z. (2017). El Practicum y las prácticas externas en la formación universitaria. Revista Practicum, 1(1). https://revistapracticum.com/index.php/io p/article/view/15/42

Guerrero, E. W. R., Mejía, I. A. G. y Zermeño, M. G. G. (2016). Propuesta de diseño de un modelo educativo integral para capacitaciones corporativas. Revista Academia y Virtualidad, 9(1), 1. http://dx.doi.org/10.18359/ravi.1496

Pérez, A. M. S. (2016). Desarrollo organizacional. Una mirada desde el ámbito académico. Educación médica, 17(1), 3-8. https://doi.org/10.1016/j.edumed.2015.09 .002

Posada, S. Á. (2016). Martha Nussbaum y la educación en humanidades. Analecta política, 6(10), 167-178. http://dx.doi.org/10.18566/apolit.v6n10.a $\underline{09}$

Lomelí-Parga, A. M., López-Padilla, M. G. y Valenzuela-González, J. R. (2016). Autoestima, motivación e inteligencia emocional: Tres factores influyentes en el diseño exitoso de un proyecto de vida de jóvenes estudiantes de educación media. Revista Electrónica Educare, 20(2), 1-22. http://dx.doi.org/10.15359/ree.20-2.4

Maldonado, M. (2019). Seminario Desarrollo Humano. Teología y vida, 60(3), 421-422. http://dx.doi.org/10.4067/S0049$\underline{34492019000300421}$ 